\title{
ANALISA PENGEMBANGAN PRODUK WARMER LAMP DENGAN MENGGUNAKAN HOQ
}

\author{
Karunia Agung Mahardini \\ Jurusan Teknik Industri, Fakultas Teknik, Universitas Bina Nusantara \\ e-mail: kmahardini@binus.edu
}

\begin{abstract}
ABSTRAK
Perkembangan dewasa ini menuntut manusia untuk melakukan segala sesuatu secara praktis, efisien dan efektif. Pemanfaatan teknologi menjadi sebuah upaya untuk mewujudkan hal tersebut didukung oleh berbagai macam peralatan. Peralatan yang mampu mendukung kinerja manusia agar mampu menghasilkan performansi yang memuaskan. Produk yang paling dekat dan sering digunakan oleh manusia serta menjadi gaya hidup pada umumnya menjadi focus pengembangan penelitian ini. Penelitian ini bertujuan untuk merancang produk yang mampu mendukung kinerja manusia yaitu pengembangan produk warmer lamp yang dalam proses pengembangannya digunakan metode House of Quality untuk menciptakan produk yang berkualitas dan sesuai dengan kebutuhan konsumen pada umumnya. Dari hasil rancangan di dapatkan sebuah produk warmer lamp yang memiliki speifikasi yang dirasa mampu memenuhi kebutuhan konsumen yang dipilih berdasarkan matriks penilaian dari enam buah konsep yang telah diajukan.
\end{abstract}

Kata kunci: Pengembangan, Produk, House of Quality.

\begin{abstract}
Nowadays, people are challenges to do everything practically, efficiently and effectively. Utilization of technology into an effort to realize it is supported by a variety of equipment. Equipment capable of supporting human performance in order to produce satisfactory performance. Products that are closest and often used by humans and become a lifestyle generally become the focus of the development of this research. This study aims to design a product that is able to support human performance is the development of warmer lamp products which in the development process used House of Quality method to create a quality product and in accordance with the needs of consumers in general. From the results of the design in getting a warmer lamp product that has a speensi that is felt able to meet the needs of consumers selected based on the assessment matrix of six concepts that have been proposed.
\end{abstract}

Keywords: Development, Product, House of Quality.

\section{PENDAHULUAN}

Perubahan gaya hidup konsumen memaksa para produsen untuk lebih berinovasi dalam mengembangkan produknya. Produk ini diharapkan dapat membantu konsumen menjalani aktivitasnya dengan lebih efektif dan efisien sehingga produk-produk multifungsi menjadi pilihan konsumen yang menginginkan hal praktis.

Produk lampu merupakan sebuah produk yang sering digunakan oleh konsumen yang bekerja di belakang meja. Selain itu produk ini sangat dekat dengan konsumen yang adalah Pelajar. Kebiasaan minum teh, kopi atau susu yang menyertai kegiataan ini menjadi peluang untuk memadukan penunjang kedua kegiatan ini melalui produk multi fungsi warmer lamp.

Untuk menciptakan sebuah produk yang sesuai dengan keinginan konsumen [1], maka perlu dilakukan Identifikasi keinginan konsumen dan perencanaan serta pengembangan produk lampu meja multifumgsi .

Sebelumnya pengembangan produk [2] dan analisis peningkatan kualitas [3] menggunakan software dan aplikasi QFD ( Quality Function Deployment (QFD). Rumah Mutu (House of Quality - HoQ) merupakan alat pokok yang digunakan dalam Quality Function Deployment (QFD) yang fokus pada persyaratan/keinginan konsumen [4]. Di dalam Rumah Mutu terdapat sebuah matrik yang menunjukkan hubungan antara kebutuhan 
pelanggan dan hal-hal teknis yang diperlukan untuk mendukung fungsi produk tersebut sehingga dapat dihasilkan produk yang dapat memuaskan pelanggan [5]. Komponen dasar dari sebuah rumah mutu adalah [6]:

1. Komponen pertama berada pada dinding sebelah kiri dari rumah tersebut. Komponen pertama adalah masukan (input) atau persyaratan dari para pelanggan. Ini adalah langkah awal dari proses tersebut dimana persyaratan konsumen yang berhubunga dengan produk tersebut ditentuukan.

2. Komponen kedua adalah matrik perencanaan yang merupakan bagian dinding kanan dari rumah. Komponen ini adalah komponen yang diasosiasikan paling dekat dengan QFD. Komponen ini digunakan untuk menterjemahkan keinginan/persyaratan konsumen ke dalam perencanaan untuk memenuhi maupun melampaui persyaratan pelanggan, penilaian kinerja perusahaan dan pesaingnya terhadap atribut-atribut konsumen dan memutuskan hal-hal yang berhubungan dengan perbaikan yang perlu dilakukan di dalam memenuhi atribut konsumen.

3. Komponen ketiga adalah puncak rumah, yang memuat karakteristik rekayasa yang mungkin berdampak kepada satu atribut pelanggan atau lebih. Salah satu pertanyaan yang akan dijawab di dalam komponen ini adalah "apakah karakteristik fabrikasi perusahaan yang ada saat ini cukup untuk memenuhi atau melampaui persyaratan para pelanggan?"

4. Komponen keempat terletak di bagian tengah rumah, yaitu tempat dimana persyaratanpersyaratan konsumen dikonversikan kedalam karakteristik fabrikasi.

5. Kelompok kelima adalah atap dari rumah tersebut yang merupakan tempat dimana pertukaran (trade-off) diidentifikasikan. Atap rumah tersebut menunjukkan interaksi antara karakteristik rekayasa yang satu dengan yang lain. Atap ini memperagakan bagaimana suatu perubahan dalam suatu sifat mungkin secara positif atau negatif mempengaruhi yang lain. Selanjutnya sebuah angka atau tanda digunakan untuk menunjukkan hubungan itu.

Berdasarkan rumah mutu tersebut maka akan dibuat suatu rancangan yang terdiri dari beberapa konsep alternatif untuk kemudian dipilih berdasarkan scoring matrix.

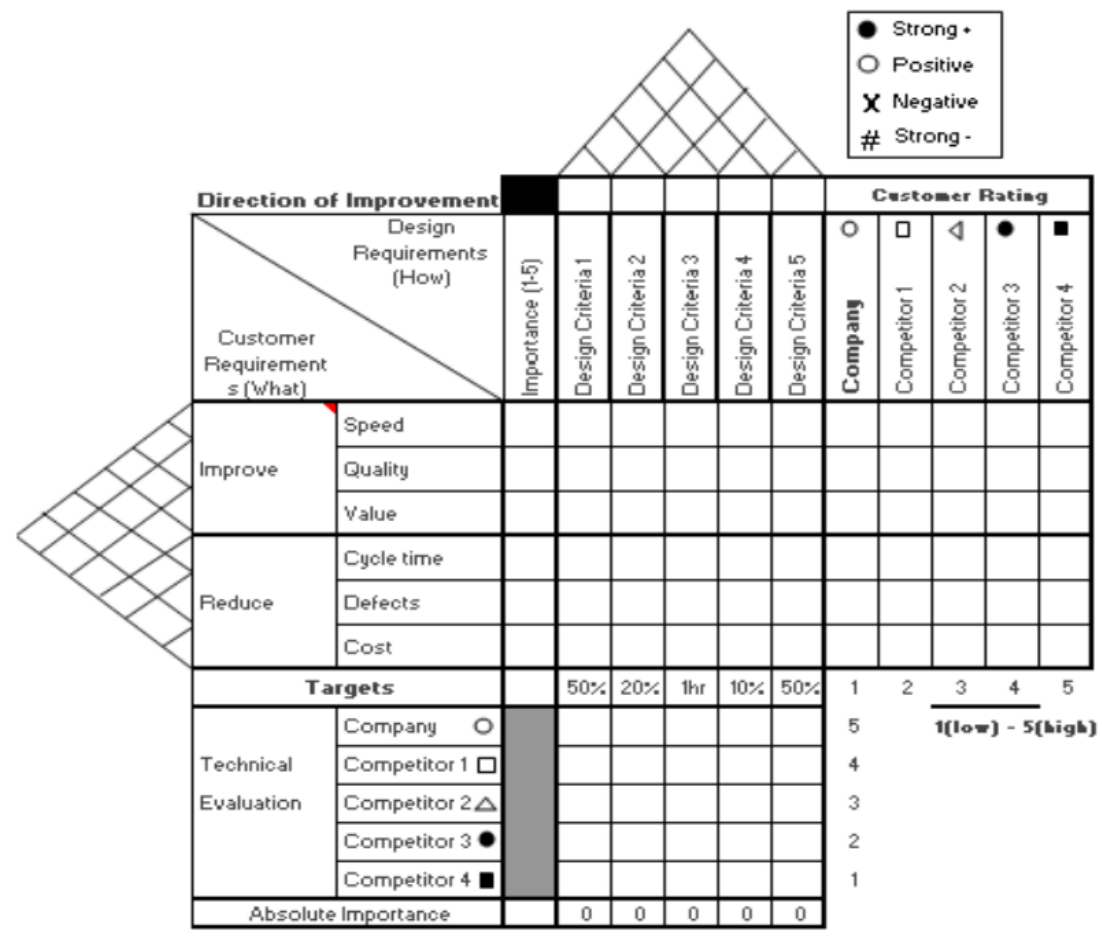

Gambar 1. Scoring Matrix 
Untuk membatasi permasalahan agar sesuai dengan tujuan penelitian, maka ditetapkan batasan masalah sebagai berikut:

1. Peneliti hanya meneliti responden yang mengerti/mengetahui atau menggunakan produk lampu meja

2. Tidak membahas mengenai biaya produksi.

3. Penelitian lebih terfokus pada proses perencanaan \& pengembangan produk lampu meja dan penghangat minuman.

\section{METODE PENELITIAN}

Pengumpulan data dilakukan dengan penyebaran kuisioner dengan jumlah responden 100 orang untuk mengetahui kebutuhan konsumen sesuai dengan target yang akan dicapai. Selanjutnya berdasarkan referensi hasil tersebut, dibuat matriks HoQ dan dilanjutkan dengan pembuatan pohon klasifikasi dimana nantinya konsep rancangan akan dibuat dan dinilai dengan metode Pugh, Konsep rancangan yang direkomendasikan dalam metode Pugh akan dibandingkan dan dipilih konsep rancangan terbaik dengan matriks penilaian [7]. Adapun tahap penelitian dapat dilihat pada Gambar 2.

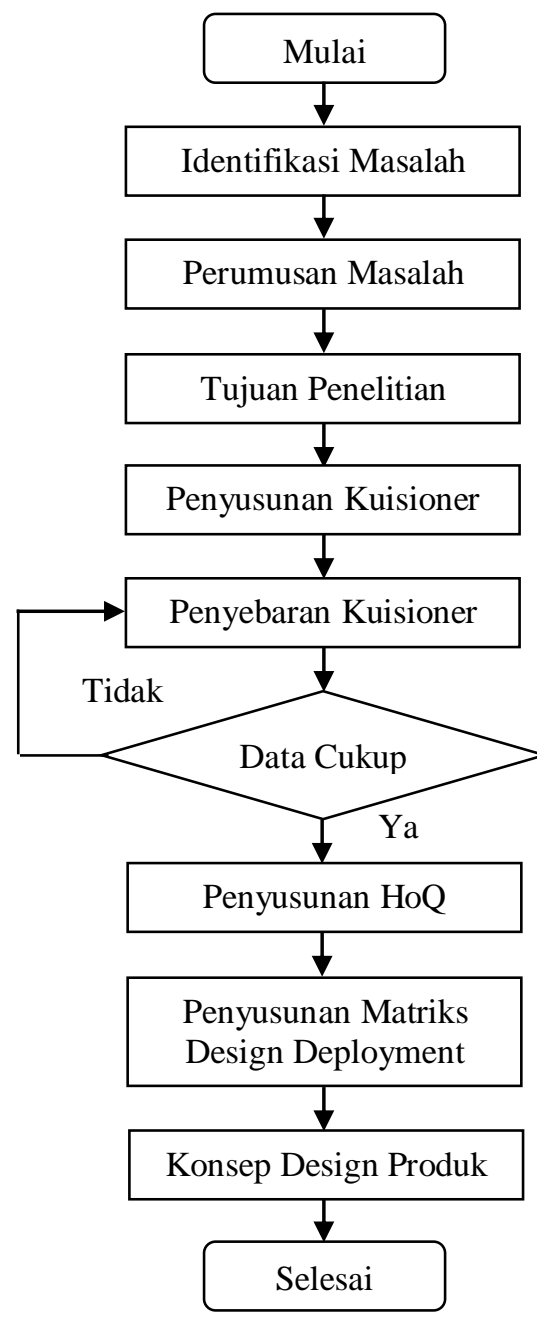

Gambar 2. Tahapan Penelitian

\section{HASIL DAN PEMBAHASAN}

Analisa kebutuhan konsumen

Berdasarkan kuisioner yang telah di sebar, maka disimpulkan bahwa kebutuhan konsumen untuk produk lampu multi fungsi adalah sebagai pada Tabel 1. 
Tabel 1. Kebutuhan konsumen

\begin{tabular}{ll}
\hline \multicolumn{2}{c}{ Kebutuhan Konsumen } \\
\hline Terang dan jangkauan cahaya luas & Unik \\
Baik untuk kesehatan & Kemasan yang baik \\
Hemat energi & Terkenal \\
Waktu pemakaian lama & Suhu yang stabil \\
Tidak mudah rusak & Proses pemanasan yang efisien \\
Mudah ditemukan & Teknologi pemanas terbaru \\
Mudah digunakan & Mudah dibersihkan \\
Bergaransi & Portable system \\
Murah & Automatic on-off system \\
\hline
\end{tabular}

\section{Seleksi Konsep}

Pada tahap ini ditampilkan beberapa alternatif material produk untuk memenuhi kebutuhan konsumen. Alternatif tersebut digambarkan melalui pohon klasifikasi yang memperlihatkan variasi material. Ada 2 bagian mendasar yang dapat menjadi variasi pembuatan produk dan berpengaruh untuk mencapai target perusahaan dalam memenuhi kebutuhan konsumen. yaitu jenis elemen pemanas dan jenis lampu seperti yang terlihat pada pohon klasifikasi (gambar 3).

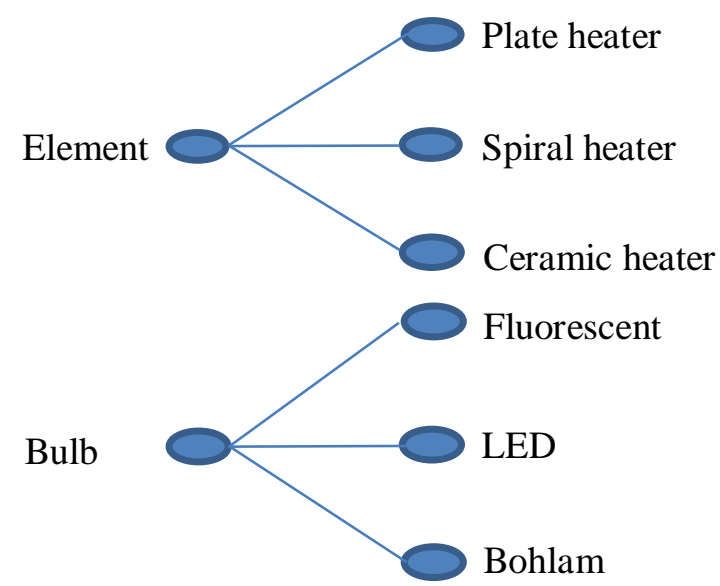

Gambar 3. Pohon Klasifikasi

Berdasarkan pohon klasifikasi maka dibuat kombinasi sebagai konsep rancangan produk. Ada 6 buah konsep yang dihasilkan seperti pada Gambar 4 berikut ini.
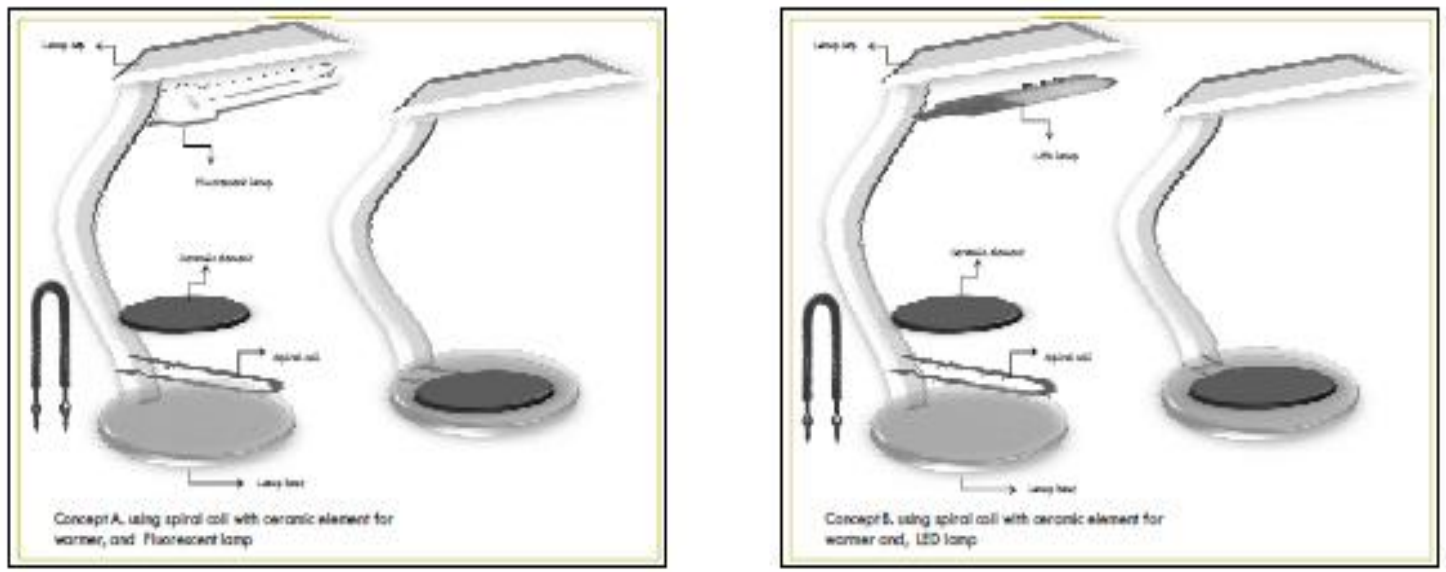

Gambar 4. Konsep Rancangan 

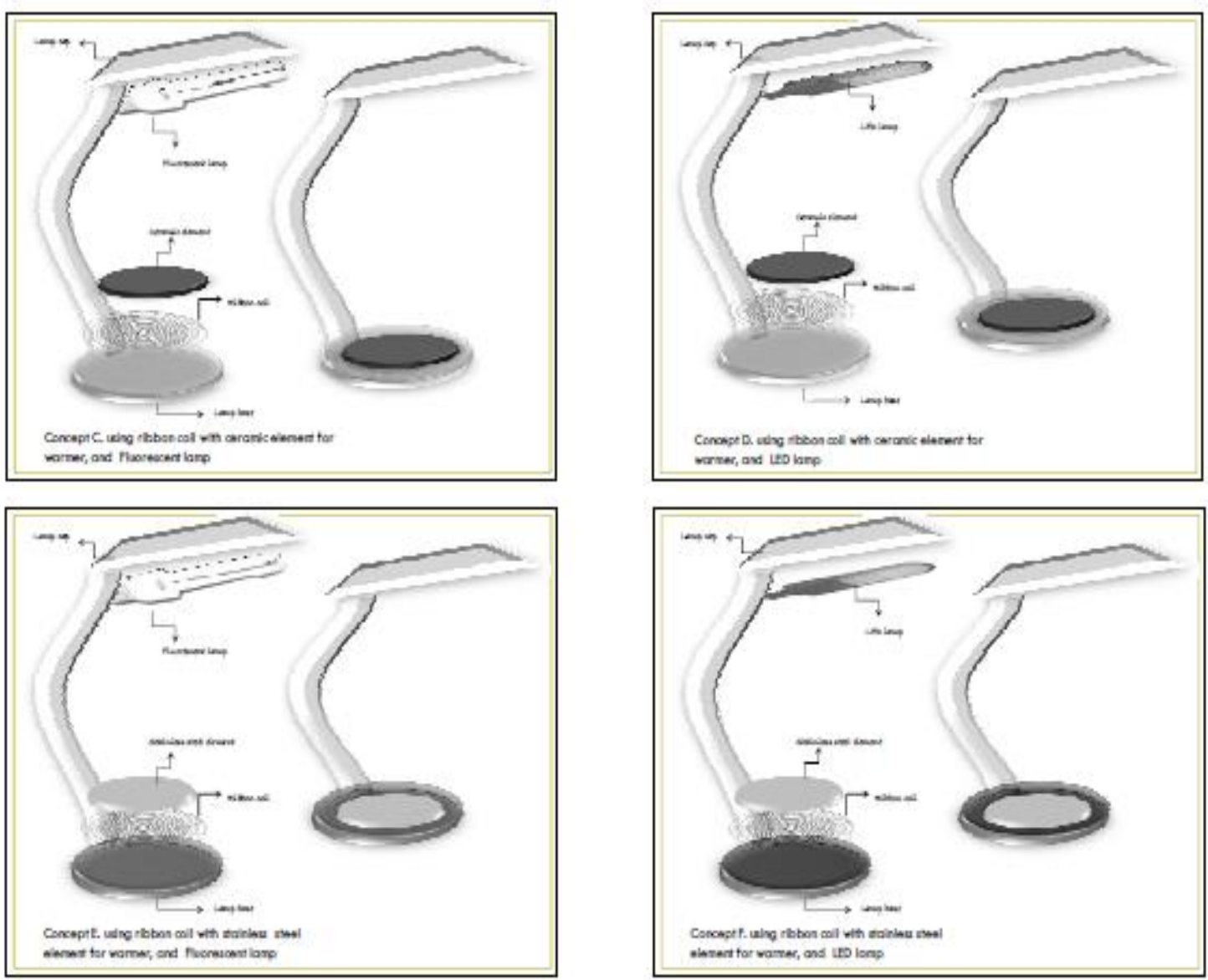

Lanjutan Gambar 4. Konsep Rancangan

Enam konsep rancangan produk tersebut merupakan kombinasi dari jenis elemen pemanas yaitu ribbon Coils dan stainless steel, juga jenis bola lampu yang terdiri atas jenis LED dan fluorocent.

Pada penyeleksian konsep dilakukan dengan membanding-bandingkan antara konsep yang satu dengan lainnya, dimana keenam konsep tersebut akan di bandingkan melihat dari kelebihan dan kekurangan yang kemudian akan dipilih satu atau dua konsep yang akan dikembangkan.

Tahapan awal dalam melakukan penyeleksian menggunakan Metode Pugh selanjutnya digunakan metode Penilaian berdasarkan Skor.

\section{Metode Pugh}

Pada proses penyeleksian dengan Metode Pugh, penilaian dilakukan dengan memberi tanda (+) untuk "lebih baik", tanda minus untuk "kurang baik" dan tanda nol (0) untuk "sama dengan". Hasil kalkulasi dari jumlah tanda-tanda tersebut akan menghasilkan nilai akhir untuk kemudian menentukan rancangan mana yang akan dipilih untuk mengikuti proses selanjutnya.

Tabel 2 menunjukkan bahwa konsep D, yaitu lampu penghangat yang menggunakan elemen Ribbon Coil untuk elemen pemanas dan lampu LED pada bola lampu, serta Konsep F, yaitu lampu penghangat yang menggunakan elemen stainless steel untuk elemen pemanas dan lampu LED pada bola lampu, memiliki nilai akhir tertinggi. 
Tabel 2. Konsep rancangan kombinasi material produk dan hasil seleksi Metode Pugh

\begin{tabular}{|c|c|c|c|c|c|c|}
\hline Kriteria seleksi & \multicolumn{6}{|c|}{ Concept } \\
\hline Hemat Energi & - & - & - & + & - & 0 \\
\hline Durability & - & - & 0 & + & 0 & - \\
\hline Perawatan mudah & 0 & 0 & 0 & + & 0 & 0 \\
\hline Jumlah 0 & 2 & 3 & 3 & 0 & 4 & 4 \\
\hline Jumlah - & 3 & 2 & 2 & 0 & 1 & 1 \\
\hline Nilai akhir & -3 & -2 & -2 & 5 & -1 & -1 \\
\hline Peringkat & 6 & 4 & 5 & 1 & 3 & 2 \\
\hline lanjutkan? & Tidak & Tidak & Tidak & $\mathrm{Ya}$ & Tidak & $\mathrm{Ya}$ \\
\hline
\end{tabular}

\section{Metode Matriks penilaian}

Dua konsep rancangan yang telah dipilih berdasarkan nilai tertinggi melalui Metode Pugh, selanjutnya dibandingkan berdasarkan bobot dan rating seperti pada Tabel 3 berikut.

Tabel 3. Metode Mariks Penilaian

\begin{tabular}{llllll}
\hline & & \multicolumn{2}{c}{$\begin{array}{c}\text { Konsep F } \\
\text { (Stainless Steel + LED) }\end{array}$} & \multicolumn{2}{c}{$\begin{array}{c}\text { Konsep D } \\
\text { (Ribbon Coil + LED) }\end{array}$} \\
\hline Kriteria Seleksi & Weight & Rating & Weighted Score & Rating & Weighted Score \\
\hline Ramah lingkungan & $25 \%$ & 2 & 0,50 & 4 & 1 \\
Hemat Energi & $35 \%$ & 3 & 0,70 & 4 & 1 \\
Durability & $20 \%$ & 2 & 0,40 & 3 & 0,6 \\
Perawatan mudah & $10 \%$ & 3 & 0,30 & 4 & 0,4 \\
Mudah digunakan & $10 \%$ & 3 & 0,30 & 4 & 0,4 \\
& Total Score & 2.2 & & 3,4 & \\
& Rank & 2 & & 1 & \\
& Continue? & No & & Yes & \\
\hline
\end{tabular}

Hasil penilaian berdasarkan skor didapatkan bahwa konsep D memiliki total nilai yang tinggi yang berarti bahwa konsep ini merupakan konsep rancangan yang memiliki karakteristik paling mendekati kebutuhan konsumen.

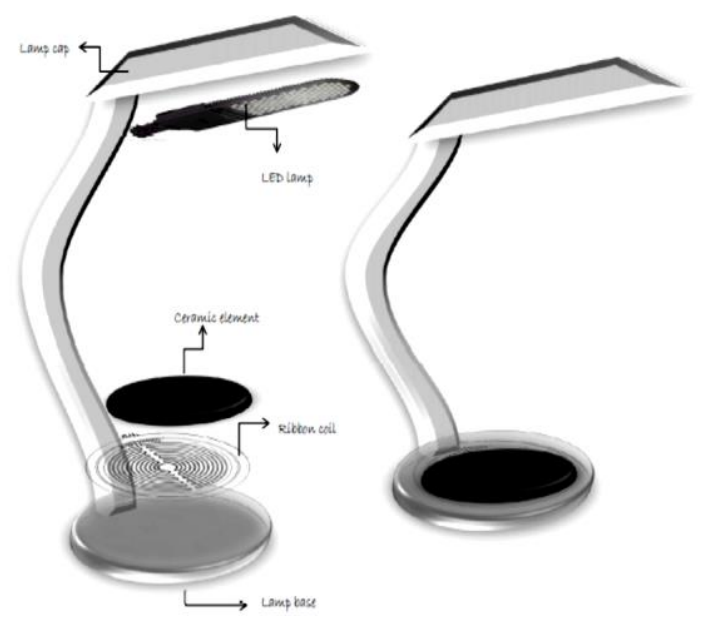

Gambar 5. Konsep Akhir Produk Warmer Lamp

\section{KESIMPULAN}

Pengembangan produk warmer lamp merupakan inovasi produk yang dirancang berdasarkan trend gaya hidup dan kebutuhan konsumen. Berdasarkan enam konsep rancangan yang dibuat, dipilih rancangan yang paling mendekati kebutuhan konsumen 
yaitu konsep warmer lamp yang menggunakan ribbon Coils sebagai elemen pemanas dan lampu LED pada bola lampunya.

\section{DAFTAR PUSTAKA}

[1]. Widodo, Imam Djati, 2003. Perencanaan dan Pengembangan Produk, TIM UII Press, Yogyakarta

[2].Shamsuddin Ahmed, Francis Amagoh, (2010) "Application of QFD in Product Development of a Glass Manufacturing Company in Kazakhstan", Benchmarking: An International Journal, Vol. 17 Issue: 2, pp.195-213.

[3].Rachela Novita, Riza Wahono, Asep Mohamad Noor, Analisis Peningkatan Kualitas Iklan Produk X dengan Menggunakan Software QFD Teknik Industri Universitas Gunadarma.

[4].Suhartini. 2012. Pengembangan Batu Onix Berdasarkan Persepsi dan Keinginan Konsumen. Prosiding Seminar Nasional Teknik Industri Waluyo Jatmiko. Surabaya.

[5].Cohen, L. 1995. Quality Function Development, How to make QFD work for you. Addition Weasley Publishing Company. Massachuset.

[6].Faure, Leste Munro and Macom Munro.1996. Implementing Total Quality Management. PT. Alex Media Komputindo, Jakarta.

[7].Ulrich, K. T. dan Eppinger, S. D. 2012. Product Design and Development.Fifth edition. McGraw-Hill. Los Angeles. 